\title{
Resistance of leaf and stem fractions of tropical forage to chewing and passage in cattle
}

\author{
BY M. N. MCLEOD, P. M. KENNEDY* AND D. J. MINSON \\ CSIRO, Division of Tropical Crops and Pastures, Cunningham Laboratory, 306 Carmody Road, \\ St Lucia, Brisbane, Queensland 4067, Australia
}

(Received 20 March 1989 - Accepted 28 August 1989)

\begin{abstract}
The voluntary intake (VI) of separated leaf and stem fractions of a grass and legume (Panicum maximum and Lablab purpureus respectively) was determined using Hereford steers fistulated at the rumen and oesophagus. VI of leaf fractions was higher than that of the stem fraction $(8.23 \mathrm{v} .3 .67 \mathrm{~kg} / \mathrm{d}, P<0.001)$ while that for the legume diets was higher than for the grass diets $(6.65 \mathrm{v} .5 .22 \mathrm{~kg} / \mathrm{d}, P<0.05)$. The total number of eating chews per day was higher on the leaf than stem fraction $\left(1.6 \times 10^{4} \mathrm{v} .9 .8 \times 10^{3}, P<\right.$ 0.05). The mean number of rumination chews $\left(2.4 \times 10^{4}\right)$ was similar $(P>0.05)$ for all four diets. The mean resistance of large particles (LP, i.e. retained on a $1.18 \mathrm{~mm}$ sieve during wet sieving) to breakdown (chews per $\mathrm{g} \mathrm{LP}$ breakdown) during eating was lower for leaf than stem fractions (8.4 v. 23.7) and lower for the grass than legume diets (10.5 v. 21.6). The mean resistance to breakdown of LP by rumination (chews per $\mathrm{g}$ LP breakdown) was lower in leaf than in stem fractions $(8.2$ v. 13.2, $P<0.01)$ and higher in grass than in legume (12.5 v. 9.0, $P<0.05)$. The resistance of $L P$ to breakdown during rumination was higher than during eating for the grass diets, but was lower for the legume. Fractional passage rates (FPR) of small particles (i.e. passing through a $1.18 \mathrm{~mm}$ sieve during wet sieving) from the reticulorumen were negatively related to dimensions of particles, with greater ease of outflow for legume than for grass particles of the same length or diameter. When corrected for content of cellulase-indigestible fibre, FPR of small particles of leaf was greater than for small stem particles. It was concluded that VI of tropical forages was associated with the resistance of L.P to breakdown by chewing during both eating and rumination and that the patterns of escape of small particles from the reticulo-rumen were only partially explicable in terms of particle dimensions, and that other properties of the particles may be of importance.
\end{abstract}

Chewing resistance: Digesta passage: Ruminant digestion

Voluntary feed intake (VI) of low-quality dried herbages is considered to be limited by the 'fill' of dry matter (DM) and its low clearance from the reticulo-rumen (Bines, 1971; Weston \& Kennedy, 1984). Before digesta can pass into the abomasum of cattle, most of the particles must be reduced below a critical size, suggested by Poppi et al. (1985) to be described by particles able to pass a screen of $1.18 \mathrm{~mm}$ pore size during wet sieving. Most of this reduction in size is achieved by chewing during eating and rumination with only $17 \%$ of the reduction attributable to digestion and detrition (McLeod \& Minson, 1988). Therefore, resistance to breakdown of forage large particles (LP) could be a major factor controlling the rate of passage of digesta from the rumen and hence the VI of forages. In addition, as the rate of passage of small particles (SP) from the reticulo-rumen is negatively related to particle size (Poppi et al. 1985), the size spectrum of the SP derived from LP breakdown might be expected to influence the rate of digesta passage from the reticulorumen. In this context it has been suggested that both size and functional specific gravity

\footnotetext{
* Present address: CSIRO Division of Tropical Animal Production, Davies Laboratory, University Road, Townsville, Queensland 4814, Australia.
} 
of particles modulate the movement of particles within the reticulo-rumen (Sutherland, 1988).

The relative importance of LP breakdown and SP passage has been discussed (Poppi et al. 1981 c) but direct experimental assessment has been rendered difficult by interactions between these factors resulting from integration of the function of the reticulo-rumen by the animal. For instance, when the requirement for LP breakdown is removed by grinding and pelleting of forages, reduction in chewing effort may reduce passage or increase it by reducing entrapment of SP in the 'raft' of buoyant particles in the dorsal rumen (Sutherland, 1988) leading to unpredictable effects on passage and fill (Weston \& Kennedy, 1984). These effects of chewing behaviour indicate that chewing and associated LP breakdown may be more significant in the control of VI than indicated by the relative content or retention times of LP and SP in the reticulo-rumen.

The present paper describes a study using leaf and stem preparations of a grass and a legume, which produce large differences in VI (Minson, 1982), designed to measure resistance of LP breakdown during eating and rumination, and rates of passage from the reticulo-rumen of SP of different sizes. Tropical forages with a high-fibre content were used to ensure that VI was limited by physical characteristics of the diet and not by the rate at which cattle could utilize energy.

\section{EXPERIMENTAL \\ Diets and animals}

Pure swards of the grass, Green panic (Panicum maximum var. trichoglume) and the legume, Lablab (Lablab purpureus $\mathrm{cv}$. Rongai), were cut after 3 months growth, chopped to $20.40 \mathrm{~mm}$ lengths, dried at $100^{\circ}$ and separated into a 'leaf' and 'stem' fraction using a gravity seed separator (Laredo \& Minson, 1973). The purity of the fractions was determined by hand separation into leaf lamina, leaf sheath and true stem. The petiole of Lablab was included in the stem fraction. Samples of the four diets were analysed for neutral-detergent fibre (NDF) (ash-free; Van Soest \& Wine, 1967), acid-detergent fibre (ADF) (ash-free; Van Soest \& Wine, 1967) and lignin (ash-free; Van Soest, 1963), and nitrogen, phosphorus, calcium, sulphur, potassium, sodium, boron, copper, manganese and zinc by emission spectroscopy (Johrison \& Simons, 1972). Other constituents of the plant were estimated as follows: hemicellulose $=$ NDF (ash-free)-ADF (ash-free); cellulose $=\mathrm{ADF}$ (ash-free, following NDF extraction)-lignin (ash-free); neutral-detergent-soluble organic matter $(\mathrm{NDSOM})=100-(\mathrm{NDF}+$ feed ash $)$.

The four feeds were offered $a d$ lib. during four periods of $15 \mathrm{~d}$ with $7 \mathrm{~d}$ adaptation in a Latin-square design to four Hereford steers fistulated at the rumen and oesophagus and weighing between 349 and $455 \mathrm{~kg}$ (mean $385 \mathrm{~kg}$ ). Feeds were offered at hourly intervals to the four steers and VI and digestibility measured as previously described (Poppi et al. 1981 a). The total number of chews and the number of eating chews were recorded by separate digital impulse counters, which were connected to a device consisting of a microswitch attached to a halter with a cable under the jaw for detecting movement (Stobbs $\&$ Cowper, 1972). A mercury switch, positioned to allow current to flow when the animal's head is in the eating position, permitted jaw movements to be recorded separately during eating. The number of rumination chews was calculated as the difference between the two readings. At the end of each period, the reticulo-rumen contents were removed through the fistula, weighed, mixed thoroughly and subsampled for particle analysis.

\section{LP breakdown}

The breakdown of LP during primary mastication was determined by measuring the proportion of LP in the diet and in the material swallowed after chewing. The swallowed material was collected via the oesophageal fistula. 
The particle spectrum (by weight) of the four diets and oesophageal extrusa was determined by the wet-sieving method developed for soil analysis (Bourget \& Kemp, 1957). The method was modified for use with forages by collecting the very small particles that passed through the bottom $0.15 \mathrm{~mm}$ screen ('fines'). Forage ( $10 \mathrm{~g})$ was soaked overnight and wet sieved using a nest of six sieves (pore sizes 4.76, 2.41, 1.18,0.50,0.31 and $0.15 \mathrm{~mm}$ ) suspended in a tank of water and oscillated through a vertical distance of $65 \mathrm{~mm}$ at a frequency of 40 strokes $/ \mathrm{min}$ for $10 \mathrm{~min}$. The particle retained on each sieve were dried and weighed. Fines were estimated on a portion of the water remaining in the tank after adjusting the volume to 40 litres. The fine particles were allowed to settle overnight, the supernatant fraction removed and the particles transferred to a tared dish, dried and weighed. The particle weight distribution in the sample was calculated as percentage (by weight) of the total weight of particles (including fines) present. Total particle DM determined in this way was water-extracted DM. LP were defined as those particles which were retained on the top three sieves $(4 \cdot 75,2.36$ and $1.18 \mathrm{~mm}$; Poppi et al. 1985) and SP as those passing the $1.18 \mathrm{~mm}$ sieve. Particles passing through a sieve with an aperture of $0.50 \mathrm{~mm}$ but retained on the sieve with an aperture of $0.30 \mathrm{~mm}$ were described as $>0.30$ particles and those passing the $0.15 \mathrm{~mm}$ screen as $<0.15$ particles. Dimensions (length and diameter) of twenty particles, selected at random from each of the sieved fractions for each animal, were measured with a Nikon profile projector. Only solitary particles, free of aggregates or debris, were measured.

\section{Reticulum motility and rumination}

Biphasic contractions of the reticulum were measured over $6 \mathrm{~h}$ using a pressure transducer attached to an open-ended catheter located in the reticulum.

\section{Marker studies}

Markers of the fluid phase (CoNaEDTA) and a chromium-labelled SP fraction (Cr-SP) of rumen digesta were prepared as described by Udén et al. (1980). The $\mathrm{Cr}$ labelled particles were prepared from Green panic and Lablab stem ground through a $1 \mathrm{~mm}$ screen, suspended in a nylon bag ( $50 \mu \mathrm{m}$ pore size) for $72 \mathrm{~h}$ in the rumen, and subsequently extracted with neutral-detergent solution (Van Soest \& Wine, 1967). After labelling with $\mathrm{Cr}$, the distributions of particles after wet sieving on screens of aperture $0.50,0.30,0.15 \mathrm{~mm}$ and those passing the $0.15 \mathrm{~mm}$ sieve, were $3.9,31.2,31.4$ and $33.4 \%$ for Green panic and $20 \cdot 2,53 \cdot 0,20 \cdot 7$ and $6 \cdot 1 \%$ for Lablab. All fractions collected contained $120-157 \mathrm{~g} \mathrm{Cr} / \mathrm{kg}$ DM.

Markers ( $4 \mathrm{~g}$ Co as CoNaEDTA in $100 \mathrm{ml}, 25 \mathrm{~g} \mathrm{Cr}-\mathrm{SP}$ ) were dosed into the rumen. Samples of rumen fluid and digesta were taken at 4, 8, 12, 28 and $32 \mathrm{~h}$ after dosing. To reduce variability due to inadequate sampling of SP and LP fractions, the LP were removed by manually sieving digesta $(10 \mathrm{~g} \mathrm{DM})$ plus water (2 litres) successively through sieves of aperture $11.5,4.0$ and $2.0 \mathrm{~mm}$. The resultant suspension was centrifuged $(15 \mathrm{~min}, 1100 \mathrm{~g})$, the supernatant fraction decanted, and the SP fraction was dried $\left(100^{\circ}\right)$ before analysing for $\mathrm{Cr}$. Co and $\mathrm{Cr}$ were determined by atomic absorption spectrophotometry after dilution for $\mathrm{Co}$, and by the procedure described by Williams et al. (1962) for $\mathrm{Cr}$.

\section{Potential digestibility}

Cellulase (EC 3.2.1.4)-insoluble fibre was used as an internal indigestible marker to correct for post-ruminal digestion of SP. After wet sieving, particles were recovered from the sieves, dried and ground through a screen of $1 \mathrm{~mm}$ aperture. Following extraction with neutral detergent, particle fractions were incubated with Onozuka FA cellulase $(6 \mathrm{~g} / 1$; extracted from Trichoderma viride; Maruzen Chemical Co. Ltd, Osaka, Japan) in acetate buffer (McLeod \& Minson, 1978) for $12 \mathrm{~d}$ at $50^{\circ}$, with the cellulase-buffer solution being 
replaced daily. After drying, residues were subjected to acid detergent (Van Soest, 1963), dried, and finally combusted at $550^{\circ}$ for $3 \mathrm{~h}$. Feed samples (ground through a $1 \mathrm{~mm}$ screen) were likewise subjected to cellulase digestion over $12 \mathrm{~d}$.

\section{Calculations}

The quantity of LP broken down during primary mastication (eating) was estimated from DM intake and the difference in proportion of LP in the feed offered and in the sample of swallowed feed collected from the oesophageal fistula. The quantity of LP broken down by secondary mastication (rumination) was estimated from the LP swallowed minus the quantity of particles excreted in the faeces. When calculated in this way no allowance is made for the LP broken down by digestion and detrition. The loss in weight of particles between feed and faeces was estimated from the increase in lignin content using the following equation:

$$
\text { feed particle DM }(\mathrm{g})=\frac{\text { faecal particle DM }(\mathrm{g}) \times \text { faecal lignin }(\mathrm{g} / \mathrm{kg} \mathrm{DM})}{\text { feed lignin }(\mathrm{g} / \mathrm{kg} \mathrm{DM})}
$$

The resistance of LP to breakdown was expressed as the number of chews required to convert $1 \mathrm{~g}$ LP into small particles and was calculated as follows:

$$
\text { resistance of } L P \text { to breakdown }=\frac{\text { number of chews }(\text { per } d)}{L P \text { broken down }(g / d)} \text {. }
$$

Apparent mean retention times (h) of DM and particulate DM in the rumen (i.e. not corrected for digestion) were calculated by dividing the rumen pool by the mean hourly consumption during the previous $48 \mathrm{~h}$ (Minson, 1966). Fractional passage rates (FPR,/d) of NDF in SP fractions were derived by dividing faecal output $(\mathrm{g} / \mathrm{d})$ by the rumen pool $(\mathrm{g})$ after correcting for digestion distal to the rumen using cellulase-insoluble fibre as an internal indigestible marker. FPR from the rumen of markers of fluid and SP were calculated as the slope of the $\log _{\mathrm{e}}$ concentration of marker $v$. time.

\section{Statistics}

The significance of differences between feeds, animals and periods was assessed by analysis of variance for a Latin square design and orthogonal comparisons were made between grass $v$. legume, leaf $v$. stem, and their interaction (Steel \& Torrie, 1980)

\section{RESULTS}

\section{Composition of the diets}

The physical characteristics of the four diets are shown in Table 1 . The leaf and stem fractions produced by gravity separation were $75-86 \%$ leaf and $98-99 \%$ stem. The leaf fractions contained both lamina and sheath, while the stem fractions contained some leaf sheath and lamina in addition to true stem. The LP content of the leaf fractions was lower than that of the stem fractions, probably because the leaf LP were more prone to shattering during drying and separation into fractions. This was particularly evident with the legume leaf fraction.

The stem fractions contained more fibre constituents and less neutral-detergent-solubles than did the leaf fractions (Table 1). Fibre (NDF, ADF) concentrations were lower in the legume fractions than in the corresponding grass fractions. Hemicellulose (NDF-ADF) concentrations were higher in the grass fractions than in the legume, with the levels in leaf being only slightly higher than those in the stem fraction. Cellulose concentrations 
Table 1. Physical characteristics and chemical composition of the four contrasting diets

\begin{tabular}{|c|c|c|c|c|}
\hline & \multicolumn{2}{|c|}{$\begin{array}{l}\text { Grass (Panicum } \\
\text { maximum) }\end{array}$} & \multicolumn{2}{|c|}{$\begin{array}{c}\text { Legume (Lablab } \\
\text { purpureus) }\end{array}$} \\
\hline & Leaf & Stem & Leaf & Stem \\
\hline \multicolumn{5}{|l|}{ Physical characteristics } \\
\hline Proportion of leaf & 0.85 & 0.01 & 0.75 & 0.02 \\
\hline Proportion of stem & $0 \cdot 15$ & 0.99 & 0.25 & $0 \cdot 98$ \\
\hline Total particles (g/kg DM*) & 770 & 790 & 760 & 800 \\
\hline Large particlest $(\mathrm{g} / \mathrm{kg} \mathrm{DM})$ & 698 & 748 & 582 & 745 \\
\hline \multicolumn{5}{|l|}{ Organic composition (g/kg DM) } \\
\hline NDSOM & 172 & 137 & 418 & 268 \\
\hline NDF (ash-free) & 683 & 751 & 456 & 610 \\
\hline ADF (ash-free) & 369 & 470 & 277 & 455 \\
\hline Hemicellulose & 314 & 288 & 179 & 156 \\
\hline Cellulose & 324 & 402 & 224 & 369 \\
\hline Lignin & 45 & 67 & 58 & 86 \\
\hline \multicolumn{5}{|l|}{ Macroelements (g/kg DM) } \\
\hline Ash & 147 & 112 & 124 & 124 \\
\hline Nitrogen & $17 \cdot 3$ & $10-8$ & $37 \cdot 0$ & 16.5 \\
\hline Phosphorus & $2 \cdot 4$ & 1.9 & $4 \cdot 0$ & $4 \cdot 1$ \\
\hline Calcium & $5 \cdot 9$ & $2 \cdot 5$ & $22 \cdot 7$ & $13 \cdot 9$ \\
\hline Sulphur & 1.9 & $1 \cdot 3$ & $2 \cdot 6$ & $2 \cdot 0$ \\
\hline Potassium & $18 \cdot 3$ & $20 \cdot 4$ & $24 \cdot 0$ & $40 \cdot 4$ \\
\hline Sodium & $11 \cdot 3$ & $12 \cdot 0$ & 0.1 & $0 \cdot 1$ \\
\hline \multicolumn{5}{|l|}{ Trace elements (mg/kg DM) } \\
\hline Boron & 11 & $<1$ & 79 & 36 \\
\hline Copper & 13 & 9 & 11 & 12 \\
\hline Manganese & 86 & 50 & 98 & 41 \\
\hline Zinc & 47 & 43 & 50 & 50 \\
\hline
\end{tabular}

DM, dry matter; NDSOM, neutral-detergent-soluble organic matter; NDF, neutral-detergent fibre; ADF, acid-detergent fibre.

* Water-extracted DM.

$\dagger$ Those particles retained on the top three sieves $(4 \cdot 75,2.36$ and $1 \cdot 18 \mathrm{~mm}$; Poppi et al. 1985).

(ADF-lignin) were higher in the grass fractions than in the corresponding legume fractions. Lignin levels were higher in the legume fractions than in the corresponding grass fractions.

Although there were no significant differences between the four feeds in ash content, the $\mathrm{P}, \mathrm{Ca}, \mathrm{S}$ and $\mathrm{K}$ contents were higher in the legume fractions than in the corresponding grass fractions, while Na was very much lower in the legume. None of these differences should have affected the VI of these forages.

\section{$V I$ and $D M$ digestibility}

Cattle ate more leaf than stem with both forages $(P<0.001)$ and more legume than grass $(P<0.05$, Table 2). No significant differences in DM digestibilities were evident between grass and legume, but the stem was more digestible $(P<0.05)$ than the leaf fraction with both forages.

\section{Mastication}

The total number of chews each day was the same for the grass and legume diets $\left(3.63 \times 10^{4}\right.$ and $3.76 \times 10^{4} ; P>0 \cdot 05$, Table 2). Cattle tended to chew more when fed on the leaf than 


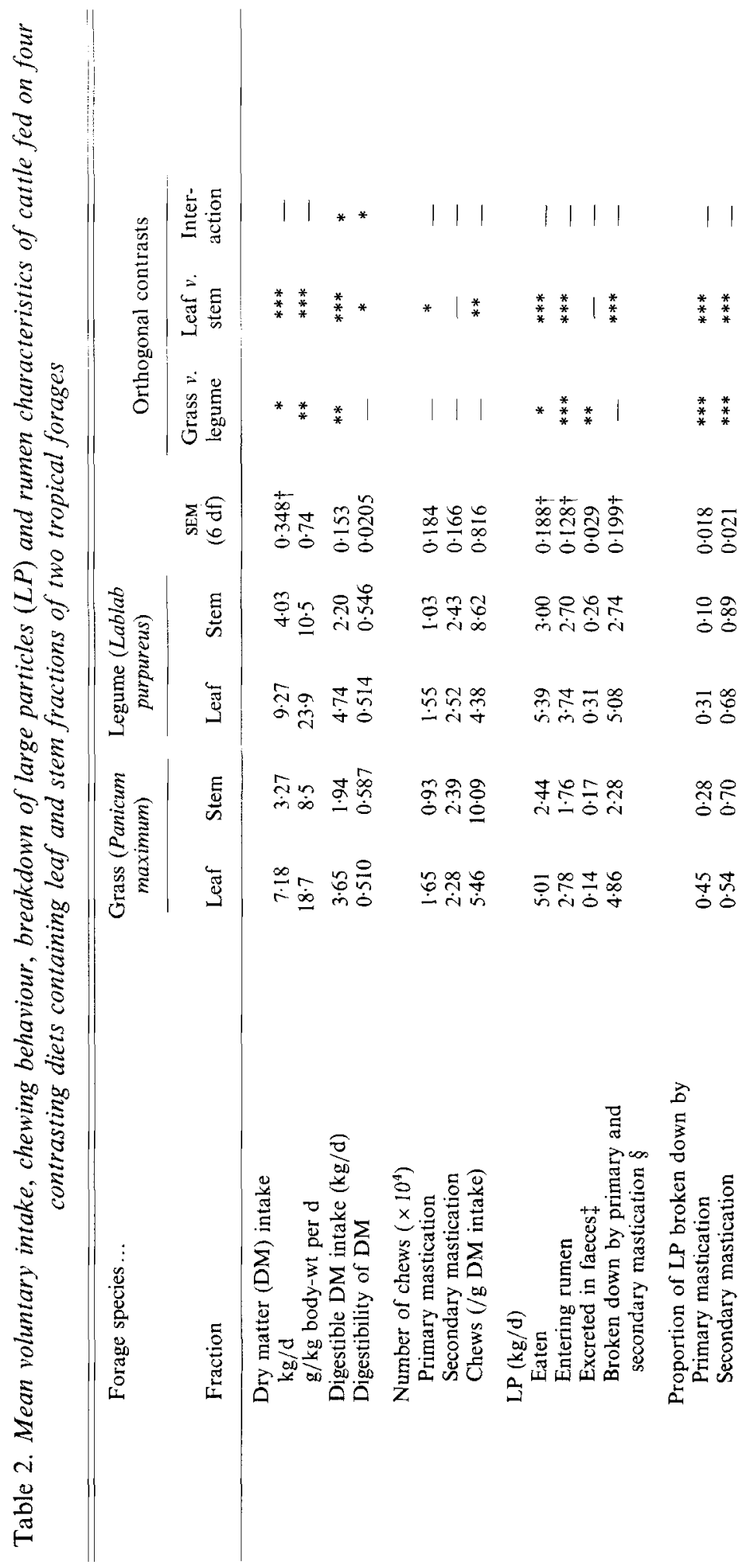




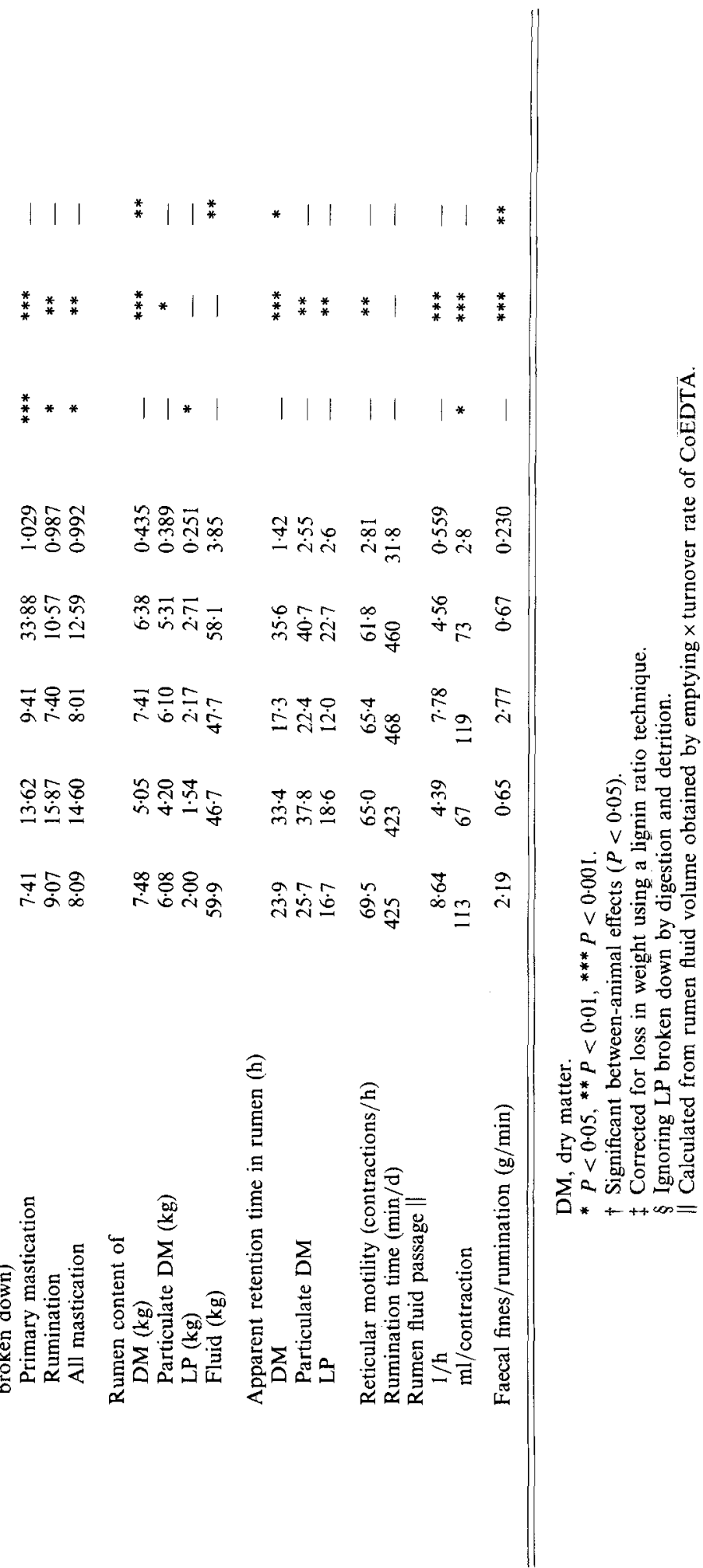


the stem fraction $\left(4.00 \times 10^{4}\right.$ v. $3.39 \times 10^{4} / \mathrm{d}$, Table 2$)$. This difference was caused by a difference in the number of primary mastication chews (leaf, $1.6 \times 10^{4}$ chews $/ \mathrm{d}$; stem, $9.8 \times 10^{3}$ chews $/ \mathrm{d} ; P<0.05$ ) and was associated with a greater intake of leaf than of stem. Rumination (secondary mastication) chews were not affected by diet, and averaged $2 \cdot 4 \times 10^{4}$ chews $/ \mathrm{d}$. The number of chews per unit DM intake varied from 4.4 to $10 \cdot 1$ chews $/ g$ with the leaf fractions requiring less chewing than the stem $(P<0.01)$.

\section{Breakdown of $L P$}

Quantities of LP eaten, entering the rumen, and excreted in the faeces were greater for the legume diet $(P<0.05$, Table 2$)$. More leaf LP were eaten and entered the rumen than stem LP but there was no corresponding difference in faecal LP excretion $(P<0.001$, Table 2$)$.

Mastication, during eating and rumination, reduced between 2.3 and $5.1 \mathrm{~kg} \mathrm{LP}$ in the forage to SP each day (Table 2). The quantity of LP broken down was higher with leaf than with stem $(4.97$ v. $2.51 \mathrm{~kg} / \mathrm{d}, P<0.001)$ and was directly related to higher intake of the leaf fraction. The quantity of LP broken down to SP was similar for the grass and legume $(3.57$ v. $3.91 \mathrm{~kg} / \mathrm{d})$. Primary mastication caused the breakdown of $38 \%$ of the LP in the leaf fraction compared with $19 \%$ in the stem fraction $(P<0.001)$. The LP in both fractions of the grass were broken down more during primary mastication than LP in the corresponding legume fractions $(P<0.001)$.

Resistance of LP to breakdown during primary mastication was lower for the leaf than stem fraction $(8.4$ v. 23.8 chews $/ g, P<0.001)$. The LP in the grass fraction had a lower resistance to breakdown during primary mastication than the LP in the legume $(10.5$ v. 21.6 chews $/ \mathrm{g}, P<0.001)$. During rumination the mean resistance to breakdown of LP was higher for grass than for legume $(12.5 v .9 .0$ chews $/ \mathrm{g} \mathrm{LP}, P<0.05)$ and higher for stem than for leaf diets $(13.2 v .8 .2$ chews $/ \mathrm{g} \mathrm{LP}, P<0.01)$. On rumination, the LP in the regurgitated digesta of the grass fractions were more resistant to breakdown than were the LP in the original forage that were broken down during primary mastication, but the opposite applied to the legume.

The quantity of rumen LP was higher $(P<0.05)$ in animals fed on legume, but was similar $(P>0.05)$ for the leaf and stem fractions. The reverse situation applied for the quantity of total rumen particles.

\section{Rumen fill and flow}

Rumen pools of DM and particulate DM, were greater $(P<0.05)$ when the animals were fed on leaf than when fed on stem (Table 2). Feeding of leaf instead of stem increased rumen fluid pools for grass, but reduced them for legume (interaction $P<0 \cdot 01$ ). Apparent retention times of DM and forage particles in the rumen were approximately $65 \%$ higher $(P<0.01)$ for stem diets than leaf diets and this was related to a $44 \%$ lower VI of the stem fraction. The movement of the greater quantity of leaf DM and SP through the rumen was associated with a higher reticular contraction rate $(P<0.01)$. Fluid flow from the rumen $(\mathrm{l} / \mathrm{h}$ and $\mathrm{ml} /$ reticular contraction) was also higher for leaf diets $(P<0.001)$. Fluid flow from the rumen $(\mathrm{l} / \mathrm{h}$ or $\mathrm{ml} /$ contraction) was correlated with $\mathrm{VI}(\mathrm{kg} \mathrm{DM} / \mathrm{d})$ according to the relationships:

$$
\begin{gathered}
\text { Fluid flow }(1 / \mathrm{h})=2.02+0.729 \mathrm{VI} \\
\text { (residual standard deviation } \left.(\mathrm{RSD}) 1.43, r^{2} 0.66, P<0.001\right) \text {. } \\
\text { Fluid flow (ml/contraction) }=39.4+9.04 \mathrm{VI} \\
\text { (RSD } \left.11.7, r^{2} 0.82, P<0.001\right) .
\end{gathered}
$$

FPR of liquid (NaCoEDTA) and particulate (Cr-SP) markers were higher $(P<0.01)$ for leaf than for stem fractions but were unaffected $(P>0.05)$ by plant species (Table 3 ). 
Table 3. Fractional passage rates of particle fractions (internal marker basis) and of markers of the fluid (CoEDTA) and particle $(C r-S P) \dagger$ phases of rumen digesta, and digestion of particles by cellulase (EC 3.2.1.4) in cattle fed on four contrasting diets containing leaf and stem fractions of two tropical forages

(Particle fractions are described in the form $>0.30$ : particles in this fraction are retained on the sieve of $0.30 \mathrm{~mm}$ pore size and pass through the previous sieve of $0.50 \mathrm{~mm}$ pore size. Fractional passage rates and post-rumen digestion are expressed on a neutral-detergent fibre basis)

\begin{tabular}{|c|c|c|c|c|c|c|c|c|}
\hline \multirow{3}{*}{$\begin{array}{l}\text { Forage species... } \\
\text { Particle fraction }\end{array}$} & \multirow{2}{*}{\multicolumn{2}{|c|}{$\begin{array}{l}\text { Grass (Panicum } \\
\text { maximum) }\end{array}$}} & \multirow{2}{*}{\multicolumn{2}{|c|}{$\begin{array}{l}\text { Legume (Lablab } \\
\text { purpureus) }\end{array}$}} & \multirow[b]{3}{*}{ SEM } & \multicolumn{3}{|c|}{ Orthogonal contrasts } \\
\hline & & & & & & \multirow{2}{*}{$\begin{array}{l}\text { Grass } v \text {. } \\
\text { legume }\end{array}$} & \multirow{2}{*}{$\begin{array}{l}\text { Leaf } v \\
\text { stem }\end{array}$} & \multirow{2}{*}{$\begin{array}{l}\text { Inter- } \\
\text { action }\end{array}$} \\
\hline & Leaf & Stem & Leaf & Stem & & & & \\
\hline \multicolumn{9}{|c|}{ Fractional passage rate $(/ d)$} \\
\hline$>0.50 \mathrm{~mm}$ & $0 \cdot 280$ & $0 \cdot 149$ & $0 \cdot 553$ & 0.416 & 0.0116 & $* *$ & * & - \\
\hline$>0.30 \mathrm{~mm}$ & 0.700 & $0-459$ & $1 \cdot 010$ & 1.010 & 0.0530 & $* *$ & 一 & - \\
\hline$>0.15 \mathrm{~mm}$ & 1.625 & 0.627 & $1 \cdot 022$ & 1.022 & 0.2348 & - & $*$ & - \\
\hline$>0.15+>0.30$ & 0.676 & $0 \cdot 384$ & 0.627 & 0.627 & 0.0218 & $*$ & $*$ & $\ldots$ \\
\hline \multicolumn{9}{|c|}{ Marker fractional passage rate $(/ \mathrm{d})$} \\
\hline CoEDTA & 3.63 & $2-49$ & 3.94 & 1.88 & $0 \cdot 375$ & - & ** & - \\
\hline $\mathrm{Cr}-\mathrm{SP}$ & 1.03 & $0-87$ & 1.48 & 0.87 & $0 \cdot 102$ & - & $* *$ & $*$ \\
\hline \multicolumn{9}{|c|}{ Relative post-rumen change in digestion $(\%)$} \\
\hline$>0.50 \mathrm{~mm}$ & $39 \cdot 5$ & $39 \cdot 5$ & $35 \cdot 0$ & $23 \cdot 9$ & $1 \cdot 21$ & $* *$ & - & - \\
\hline$>0.30 \mathrm{~mm}$ & $37 \cdot 7$ & $33 \cdot 5$ & $25 \cdot 0$ & $33 \cdot 8$ & $5 \cdot 42$ & - & - & - \\
\hline$>0.15 \mathrm{~mm}$ & $27 \cdot 2$ & 18.9 & 262 & 36.9 & 0.80 & - & - & $*$ \\
\hline
\end{tabular}

${ }^{*} P<0.05, * * P<0.01, * * * P<0.001$.

$\dagger$ Chromium-labelled small particle fraction.

Apparent FPR for rumen particle fractions, not corrected for internal marker content, are shown in Fig. 1(a). Higher rates for legume than for grass diets $(P<0.01)$ were observed for $>1.18,>0.50$ and $>0.30$ particles. When apparent FPR was related to measured dimensions of particles, it was clear that, on average, legume particles moved from the reticulo-rumen or were digested in the caecum, or both, with greater ease than grass particles. Also, leaf particles tended to flow faster than stem particles at a given particle length or diameter (Fig. $1(b, c)$ ).

When FPR of NDF in particles was corrected for post-rumen digestion by reference to an internal marker (cellulase-insoluble fibre), significant differences were found in FPR of the $>0.05,>0.30$ and $>0.15$ particles with the following trends being evident (Table 3 ): (a) FPR tended to be negatively related to particle size; (b) FPR for legume diets was greater than for grass diets for $>0.50$ and $>0.30$ particles, but not for $>0.15$ particles; (c) the absolute difference between FPR of leaf compared with stem diets increased with decreasing particle size, with the principle effect attributed to the steers fed on Green panic. The FPR of $(>0.15+>0.30+>0.50)$ particles was greater for Lablab than for Green panic $(P<0.05)$ and for leaf than for stem fractions $(P<0.05)$. These differences were largely due to the low FPR of Green panic stem.

Correction for content of cellulase-insoluble fibre increased FPR by 9,8 and $8 \%$ respectively for $>0.50,>0.30$ and $>0.15$ particles when compared with calculations on an uncorrected basis. The bias introduced by not correcting for the internal marker was somewhat variable; FPR across the three particle groups calculated by reference to 

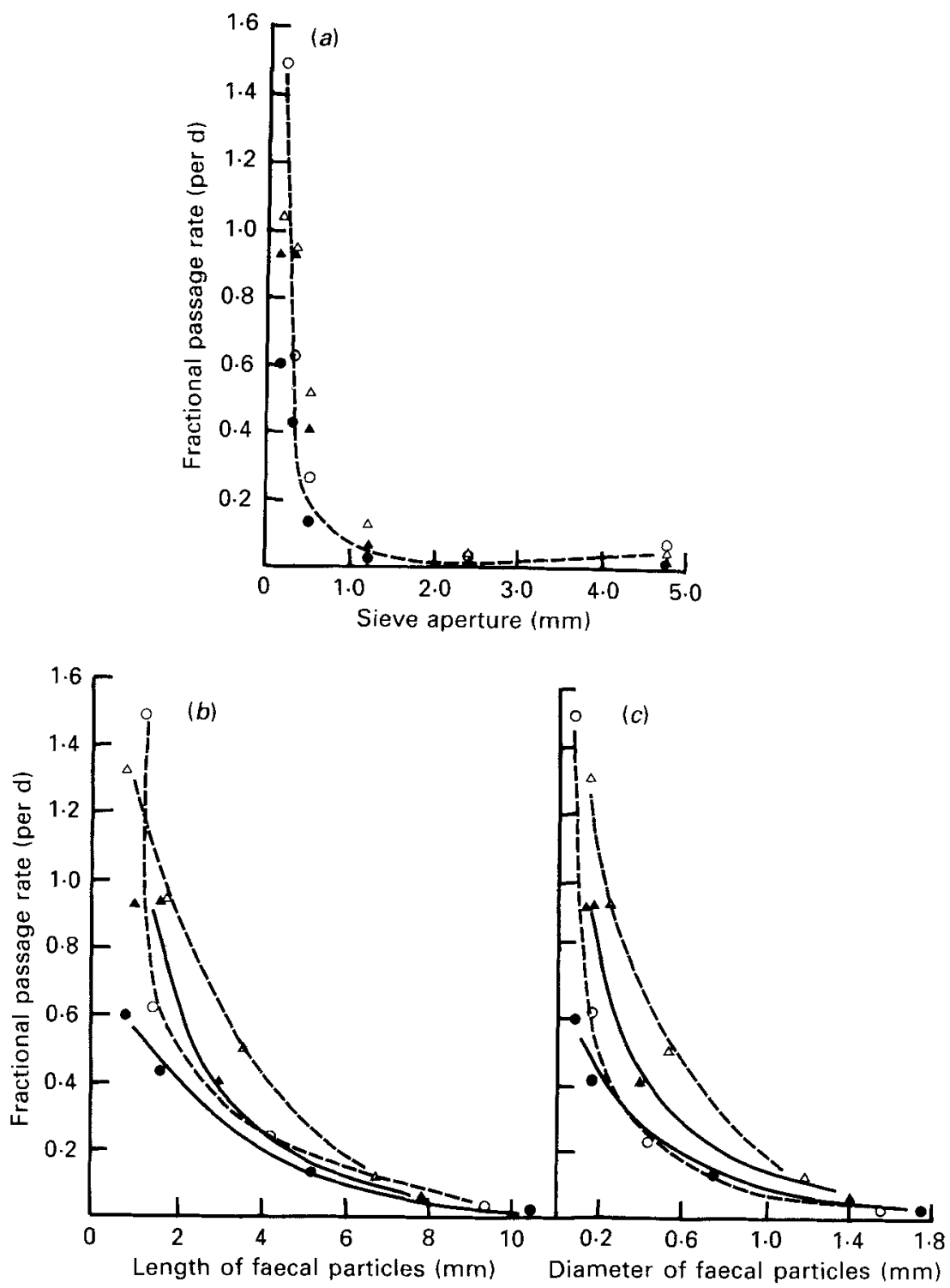

Fig. 1. Relationship of apparent passage outflow rate (not corrected for internal marker) of particles retained on sieves $v$. (a) screen aperture of sieves, $(b)$ mean length and $(c)$ mean diameter of particles. Grass (Panicum maximum) leaf $(O)$, stem (O); legume (Lablab purpureus) leaf $(\triangle), \operatorname{stem}(\mathbf{A})$.

cellulase-insoluble fibre exceeded apparent FPR by 13,6,9 and 7\% for grass leaf and stem and legume leaf and stem respectively.

Mean length $(\mathrm{mm})$ of faecal particles was related to mean length $(\mathrm{mm})$ of rumen particles retained on sieves of pore size $0 \cdot 15,0 \cdot 31,0 \cdot 50,1 \cdot 18$ and $2.41 \mathrm{~mm}$ as follows:

Green panic leaf and stem

faecal length $=0 \cdot 126+0.931$ rumen length

(RSD $1 \cdot 25, r^{2} 0 \cdot 91, P<0 \cdot 001$ ). 


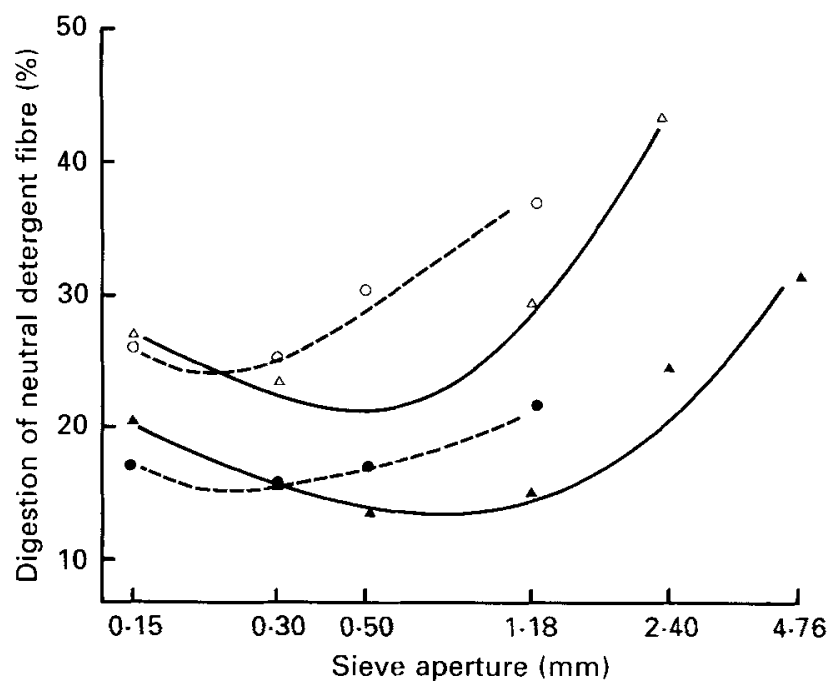

Fig. 2. Digestion by cellulase (EC 3.2.1.4) of neutral-detergent fibre (NDF) in sieved particles of rumen digesta as a function of screen aperture of sieves on which particles are retained. Grass (Panicum maximum) leaf $(O)$, stem (O); legume (Lablab purpureus) leaf $(\triangle)$, stem $(\boldsymbol{\Delta})$.

Lablab leaf and stem

$$
\begin{aligned}
& \text { faecal length }=0.729+0.566 \text { rumen length } \\
& \text { (RSD } \left.0.435, r^{2} 0.98, P<0.001\right) .
\end{aligned}
$$

Digestion of NDF by cellulase in rumen particles occurred to a substantially greater extent $(P<0.001)$ in leaf than in stem diets. Within diets, the extent of cellulase digestion of particle fractions from rumen digesta decreased with decreasing screen sizes to a minimum for $>0.31$ (Green panic) and 0.50 (Lablab) and thereafter increased for smaller particles (Fig. 2). Digestion by cellulase over $12 \mathrm{~d}$ removed $42,27,48$ and $33 \%$ of the NDF in Green panic leaf and stem, and Lablab leaf and stem fractions, respectively.

Fine $(<0.15)$ particles comprised more $(33 v .21 \%, P<0.001)$ faecal particulate matter in animals fed on leaf than in those fed on stem. Appearance of fine particles in the faeces per min of rumination was greater in leaf than in stem fractions and greater in Lablab leaf than for Green panic diets (Table 2).

\section{Relations with $V I$}

The VI of the four contrasting feeds was negatively related to the number of chews required per g DM (Fig. 3), with a lower number of chews for the leaf fraction than for the stem fraction. The higher intake of the leaf fraction appeared to be associated with the lower resistance of the LP fraction to breakdown during both primary and secondary mastication (Table 2).

Voluntary intake of the four diets were also positively related to rates of passage of markers of the fluid $(P<0.01)$ and SP $(P<0.05)$ fractions. In addition VI $(\mathrm{kg} / \mathrm{d})$ of stem diets was related to $\mathrm{DM}$ in the reticulo-rumen as follows:

$$
\begin{gathered}
\mathrm{VI}=0.909+0.480 \text { rumen DM pool } \\
\left(\text { RSD } 0.191, r^{2} 0.96, P<0.001\right) .
\end{gathered}
$$




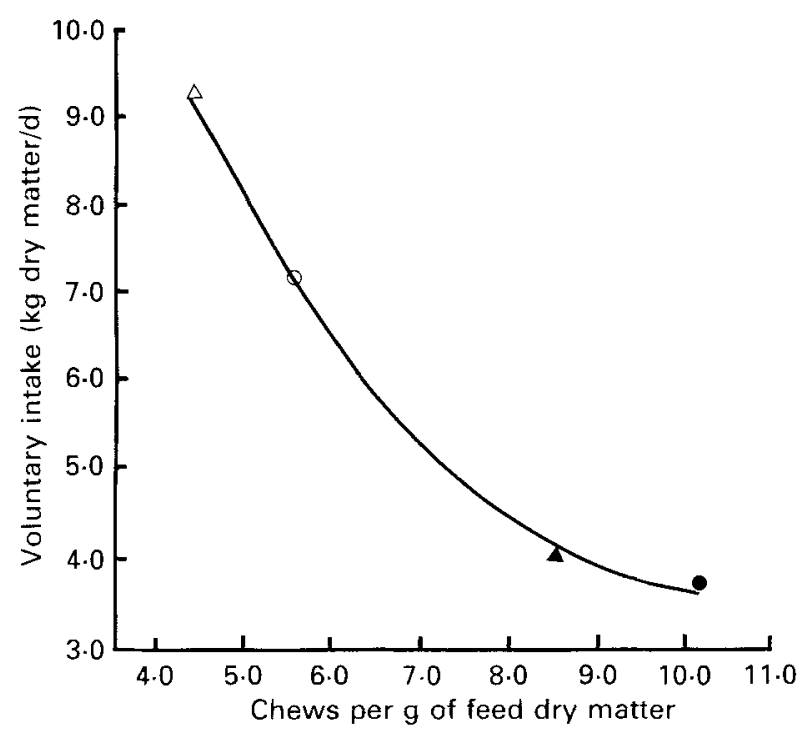

Fig. 3. Relation between voluntary intake $(y)$ and the number of eating and ruminating chews required per unit of feed $(x)$. Grass (Panicum maximum) leaf $(O)$, stem $(\mathbf{O})$; legume (Lablab purpureus) leaf $(\Delta)$, stem $(\boldsymbol{\Delta})$.

Regression: $y=20 \cdot 2-3 \cdot 2 x+0 \cdot 15 x^{2}, n 4, r 0 \cdot 99$, SE of the estimate $0 \cdot 22$.

\section{DISCUSSION}

Breakdown of LP appears to be required before a particle may be cleared from the reticulo-rumen (Poppi et al. 1985) and the present study has indicated the importance of chewing in the clearance of contrasting forages with very different chemical and morphological properties, as shown by the relationship of VI to the resistance of forage to breakdown during chewing (Fig. 3). The higher VI of the leaf than the stem fraction of both the grass and legume was associated with a lower proportion of LP in the leaf fraction, a greater number of primary chews and lower resistance of the leaf LP to breakdown to SP during primary mastication. The combined effect led to three to five times more leaf than stem LP being broken down by primary mastication. The intake of the leaf fraction was further enhanced by the high level of neutral-detergent-soluble organic matter and the smaller proportion of LP (Table 1).

The number of ruminating chews each day was similar for all four feeds and was not a factor contributing to the higher intake of the leaf fraction. However, the resistance to breakdown of LP in the leaf fraction regurgitated during rumination was again lower than that of the stem fraction indicating greater fragility. The size distribution of SP in the rumen and in the faeces also suggested that the greater fragility of leaf diets resulted in finer particles.

The VI of legume leaf was $29 \%$ higher than that of grass leaf. This appears to be only partially explained by the lower intake of LP in the legume $(4.23 \mathrm{~kg})$ than in the grass leaf $(4.90 \mathrm{~kg})$, due to the lower content of cell wall material in the legume (Table 1). The higher VI of the stem fraction of the legume appears to be associated with a low resistance to breakdown during rumination.

SP resulting from chewing, digestion and detrition of the forage are retained in the 
reticulo-rumen for various lengths of time before passing through the reticulo-omasal orifice. To what extent VI is limited by the rate of passage of those SP from the reticulorumen has not been established but it is known that there are only small differences in VI of contrasting forages once the LP are removed by grinding and pelleting (Heaney et al. 1963). The differences in rate of passage of fluid and SP in the present study provides some evidence of the effect of VI of forage on rumen variables. The positive association of fluid flow from the reticulo-rumen and VI observed in the present experiment is in agreement with previous studies using similar diets (Hendricksen et al. 1981; Poppi et al. 1981 b), although the quantity of fluid flowing per $\mathrm{kg}$ DM intake was higher in the present experiments. The higher flow in cattle given leaf was attributed mainly to the larger quantity of SP that left the rumen and a higher fluid passage per reticular contraction, although the latter appears to be less important.

A significant finding from the present work is that rates of passage of particles of the same length or diameter varied markedly between diets (Fig. $1(b, c)$ ). The results in Fig. $1(b, c)$ also confirm the finding of Dixon \& Milligan (1985), Egan \& Doyle (1985) and Poppi et al. (1985), among others, that ease of particle flow is proportional to particle size. The faster passage of legume compared with grass has been ascribed to differences in particle shape (Troelsen \& Campbell, 1968), but may also reflect higher functional specific gravity or lower buoyancy of legume particles. In the study of Hooper \& Welch (1985), values $(1 \cdot 2-1 \cdot 4$; Welch, 1986) of specific gravity conducive to rapid passage were achieved more rapidly in legumes than in grasses, perhaps due to the presence of fewer hydrophobic molecules in legume cell walls (see Gates et al. 1987). In the present experiment, the relationship between faecal and rumen particle lengths collected on the same sieves during wet sieving differed markedly between grass and legume diets (Eqns (3) and (4)). As the wetsieving process is influenced by specific gravity as well as dimensions of particles, this result is suggestive of a greater change in functional specific gravity for Lablab particles while passing through the gastrointestinal tract, perhaps due to selection for passage from the reticulum of less buoyant particles.

Further differences between the legume and grass diets were evident in patterns of cellulase-available NDF (Fig. 2). The content of cellulase-available NDF in $>0.15$ particles of leaf and stem fractions of legume was equivalent to that of material from sieves of theoretical aperture 1.0 and $2.3 \mathrm{~mm}$ respectively, whereas for $>0.15$ particles of grass leaf and stem, the theoretical sieves had apertures of 0.35 and $0.51 \mathrm{~mm}$. We postulate that these differences, which were associated with lower resistance to breakdown of legume LP during rumination (Table 2), suggest more extensive fragmentation of legume LP to $>0.15$ particles than for grass LP, and for relatively greater selection for passage of extensively digested $>0.15$ legume particles, with those remaining in the rumen being relatively buoyant and digestible.

The above discussion has highlighted differences in LP breakdown observed in contrasting forages of high-fibre content requiring prolonged rumination $(7 \mathrm{~h} / \mathrm{d})$. If chewing assists in the passage of SP through effects on 'raft' reduction and accelerated passage of SP from the reticulum, as well as its requirement for LP breakdown, then the calculated value of 'resistance to LP breakdown' during chewing appears useful in the prediction of VI. Future validation of the use of 'resistance to LP breakdown to chewing' in prediction of VI would suggest that laboratory measurements of forage fragility of good predictive power could be achieved. Such a technique would require criteria of particle size which could be related to those found in ruminants.

It is concluded that VI of tropical forages was associated with the resistance of LP to breakdown to SP by chewing during both eating and rumination, and that the patterns of 
escape of particles from the reticulo-rumen were only partially explicable in terms of particle dimensions, and that other properties of the particles may be of importance. The role of plant anatomy in the resistance of forages to breakdown during chewing and the presence of specialized structures which affect microbial digestion remain to be resolved.

\section{REFERENCES}

Bines, J. A. (1971). Metabolic and physical control of food intake in ruminants. Proceedings of the Nutrition Society 30, $116-122$.

Bourget, S. J. \& Kemp, J. D. (1957). Wet sieving apparatus for stability analysis of soil aggregates. Canadian Journal of Soil Science 37, 60.

Dixon, R. M. \& Milligan, L. P. (1985). Removal of digesta components from the rumen of steers determined by sieving techniques and fluid, particulate and microbial markers. British Journal of Nutrition 53, 347-362.

Egan, J. K. \& Doyle, P. T. (1985). Effect of intraruminal infusions of urea on the response in voluntary intake by sheep. Australian Journal of Agricultural Research 36, 483-495.

Gates, R. N., Klopfenstein, T. J., Waller, S. S., Stroup, W. W., Britton, R. A. \& Anderson, B. F. (1987). Influence of thermo-ammoniation on quality of warm season grass hay for sheep. Journal of Animal Science $\mathbf{6 4}$ $1821-1834$

Heaney, D. P., Pigden, W. J., Minson, D. J. \& Pritchard, G. I. (1963). Effect of pelleting on energy intake of sheep from forages cut at three stages of maturity. Journal of Animal Science 22, 752-757.

Hendricksen, R. E., Poppi, D. P. \& Minson, D. J. (1981). The voluntary intake, digestibility and retention time by cattle and sheep of stem and leaf fractions of a tropical legume (Lablab purpureus). Australian Journal of Agricultural Research 32, 389-398.

Hooper, A. P. \& Welch, J. G. (1985). Functional specific gravity of ground hay samples in ionic solutions. Journal of Dairy Science $\mathbf{6 8}, 848-856$.

Johnson, A. D. \& Simons, J. G. (1972). Direct reading emission spectroscopic analysis of plant tissue using a briquetting technique. Communication in Soil Science and Plant Analysis 3, 1-9.

Laredo, M. A. \& Minson, D. J. (1973). The voluntary intake, digestibility and retention time by sheep of leaf and stem fractions of five grasses. Australian Journal of Agricultural Research 24, 875-888.

McLeod, M. N. \& Minson, D. J. (1978). The accuracy of the pepsin-cellulase technique for estimating the dry matter digestibility in vivo of grasses and legumes. Animal Feed Science and Technology 3, 277-287.

McLeod, M. N. \& Minson, D. J. (1988). Large particle breakdown by cattle eating ryegrass and alfalfa. Journal of Animal Science 66, 992-999.

Minson, D. J. (1966). The apparent retention of food in the reticulo-rumen at two levels of feeding by means of an hourly feeding technique. British Journal of Nutrition 20, 765-773.

Minson, D. J. (1982). Effects of chemical and physical composition of herbage upon intake. In Nutritional Limits to Animal Production from Pastures, pp. 167-182 [J. B. Hacker, editor]. Farnham Royal: Commonwealth Agricultural Bureaux.

Poppi, D. P., Hendrickson, R. E. \& Minson, D. J. (1985). The relative resistance to escape of leaf and stem particles from the rumen of cattle and sheep. Journal of Agricultural Science, Cambridge 105, 9-14.

Poppi, D. P., Minson, D. J. \& Ternouth, J. H. (1981 a). Studies of cattle and sheep eating leaf and stem fractions of grasses. I. The voluntary intake, digestibility and retention time in the reticulorumen. Australian Journal of Agricultural Research 32, 99-108.

Poppi, D. P., Minson, D. J. \& Ternouth, J. H. (1981 b). Studies of cattle and sheep eating leaf and stem fractions of grasses. II. Factors controlling the retention of feed in the reticulorumen. Austrialian Journal of Agricultural Research 32, 109-121.

Poppi, D. P., Minson, D. J. \& Ternouth, J. H. (1981 c). Studies of cattle and sheep eating leaf and stem fractions of grasses. III. The retention time in the rumen of large feed particles. Australian Journal of Agricultural Research 32, 123-137.

Steel, R. G. D. \& Torrie, J. H. (1980). Principles and Procedures of Statistics: A Biometrical Approach. New York : McGraw-Hill

Stobbs, T. H. \& Cowper, J. L. (1972). Automatic measurement of the jaw movements of dairy cows during grazing and rumination. Tropical Grasslands 6, 107-112.

Sutherland, T. M. (1988). Particle separation in the forestomachs of sheep. In Aspects of Digestive Physiology in Ruminants, pp. 43-73 [A. Dobson and M. J. Dobson, editors]. Ithaca: Comstock Publishing Associated.

Troelsen, J. E. \& Campbell, J. B. (1968). Voluntary consumption of forages by sheep and its relation to the size and shape of particles in the digestive tract. Animal Production 10, 289-296.

Udén, P., Collucci, P. E. \& Van Soest, P. J. (1980). Investigation of chromium, cerium and cobalt as markers in digesta, rate of passage studies. Journal of the Science of Food and Agriculture 31, 625-632.

Van Soest, P. J. (1963). Use of detergents in the analysis of fibrous feeds. II. A rapid method for the determination of fibre and lignin. Journal of the Association of Official Agricultural Chemists 46, 829-835. 
Van Soest, P. J. \& Wine, R. H. (1967). Use of detergents in the analysis of fibrous feeds. IV. Determination of plant cell-wall constituents. Journal of the Association of Official Agricultural Chemists 50, 50-55.

Welch, J. G. (1986). Physical parameters of fibre affecting passage from the rumen. Journal of Dairy Science 69, $2750-2754$.

Weston, R. H. \& Kennedy, P. M. (1984). Various aspects of reticulorumen digestive function in relation to diet and digesta particle size. In Techniques in Particle Size Analysis of Feed and Digesta in Ruminants, pp. 1-27 [P. M. Kennedy, editor]. Edmonton: Canadian Society of Animal Science.

Williams, C. H., David, D. J. \& Iismaa, O. (1962). The determination of chromic oxide in faeces samples by atomic absorption spectrometry. Journal of Agricultural Science, Cambridge 59, 381-385. 